\title{
ANALISIS PENDAPATAN PETERNAK SAPI PERAH KECAMATAN MOJOSONGO DAN CEPOGO, KABUPATEN BOYOLALI
}

(Income Analyze of Dairy Farmers Mojosongo, and Cepogo District, Boyolali Regency)

\author{
Premisti, P. U. L. ${ }^{1}$, A. Setiadi ${ }^{2}$ dan W. Sumekar ${ }^{3}$ \\ 1) Mahasiswa Fakultas Peternakan Dan Pertanian Universitas Diponegoro \\ Kampus drh. Soejono Koesoemowardojo, Jl. Prof. H. Soedarto, SH Tembalang Semarang \\ 50275 \\ E-mail : putriutamilintang@gmail.com \\ ${ }^{\text {2,3) }}$ Fakultas Peternakan dan Pertanian, Universitas Diponegoro \\ Kampus drh. R. Soejono Kusumowardojo Tembalang, Semarang 50275
}

Diterima : 8 Januari 2016

Disetujui : 25 Juni 2016

\begin{abstract}
The purpose of this study was to determine income dairy farmers Mojosongo, and Cepogo District, to know the difference dairy farmers income Mojosongo, and Cepogo District, Kabupaten Boyolali. Research was held in Oktober-November 2015. Determination location selected using purposive method with criteria district that has the most dairy cows in the district boyolali. The method used in this research was a survey method. Determination of sample was purposive sampling method. Determination of respondents to represent the population conducted by slovin formula. The number of samples was 66 respondents. The primary data were obtained directly through observation at the farm activities and interviews with respondents using a questionnaire that has been prepared. The results showed that the average income of farmers Mojosongo district was IDR 1,327,996.00/month and farmers Cepogo District was IDR 2,312,258.00/month.
\end{abstract}

Keywords: Income, dairy cows, farmers

\begin{abstract}
ABSTRAK
Tujuan dari penelitian ini adalah untuk mengetahui pendapatan yang diperoleh peternak Kecamatan Mojosongo, dan Kecamatan Cepogo, dan untuk mengetahui perbedaan pendapatan Kecamatan Mojosongo, dan Kecamatan Cepogo, Kabupaten Boyolali. Penelitian dilaksanakan pada bulan Oktober-November 2015. Penentuan lokasi dipilih menggunakan metode purposive dengan kriteria kecamatan yang memiliki usaha ternak sapi perah terbanyak di Kabupaten Boyolali. Metode penelitian yang digunakan dalam penelitian ini menggunakan metode survei. Penentuan sampel responden dilakukan dengan metode purposive sampling. Penentuan jumlah responden untuk mewakili populasi dilakukan dengan perhitungan rumus Slovin. Jumlah sampel yang diambil sebanyak 66 responden. Data primer diperoleh secara langsung melalui kegiatan observasi di peternakan dan kegiatan wawancara dengan responden menggunakan kuisioner yang telah disiapkan. Hasil penelitian menunjukan rata-rata pendapatan peternak Kecamatan Mojosongo Rp 1,327,996.00/bulan, dan peternak di Kecamatan Cepogo sebesar Rp $2,312,258.00 /$ bulan.
\end{abstract}

Kata Kunci : pendapatan, sapi perah, peternak 


\section{PENDAHULUAN}

Peternakan sapi perah rakyat masih mempunyai keterbatasan dalam menjalankan usahanya, antara lain dalam hal tingkat pendidikan dan ketrampilan. Keterbatasan ini menjadikan peternak sapi perah rakyat dalam menjalankan usahanya tanpa memperhitungkan besarnya modal yang dipergunakan, biaya produksi yang telah dikeluarkan untuk operasional usahanya dan pendapatan yang diperoleh. Peternak cenderung tidak menghitung biaya yang telah di keluarkan dengan yang di terima (Royan, 2009).

Indikator keberhasilan dari usaha tani atau usaha ternak dapat dilihat dari besarnya pendapatan yang diperoleh petani atau peternak dalam mengelola suatu usahatani atau usahaternak. Semakin besar pendapatan yang diterima petani atau peternak akan semakin besar pula tingkat keberhasilan usahatani maupun usahaternaknya. Usaha tani dikatakan berhasil apabila pendapatan cukup digunakan untuk membayar sarana produksi termasuk biaya angkutan, cukup untuk membayar biaya bunga modal dan cukup untuk membayar upah tenaga kerja yang dibayar atau dalam bentuk upah lainnya (Soekartawi, 1995).

Penelitian ini bertujuan untuk mengetahui pendapatan yang diperoleh peternak Kecamatan Mojosongo, dan Kecamatan Cepogo, serta untuk mengetahui perbedaan pendapatan peternak Kecamatan Mojosongo dan Kecamatan Cepogo.

\section{MATERI DAN METODE}

Penelitian ini dilakukan di Kecamatan Mojosongo, dan Kecamatan Cepogo. Penentuan lokasi dipilih menggunakan metode purposive dengan kriteria kecamatan yang memiliki usaha ternak sapi perah tertinggi di Kabupaten Boyolali.

Metode pengumpulan data yang digunakan dalam penelitian ini adalah metode observasi dan wawancara. Data yang diperoleh meliputi data primer dan data sekunder. Data primer diperoleh secara langsung melalui kegiatan observasi di peternakan dan kegiatan wawancara dengan responden menggunakan kuisioner yang telah disiapkan. Metode analisis yang digunakan adalah

Analisis pendapatan untuk mengetahui atau menghitung besarnya pendapatan usahatani ternak sapi perah (Soekartawi, 1993) digunakan persamaan:

$$
\pi=\mathrm{TR}-\mathrm{TC}
$$

Keterangan :

$\pi=$ pendapatan (rupiah/bulan)

$\mathrm{TC}=$ biaya produksi (rupiah/bulan)

$\mathrm{TR}=$ penerimaan (rupiah/bulan)

\section{HASIL DAN PEMBAHASAN}

\section{Keadaan Umum Daerah Penelitian}

Kabupaten Boyolali merupakan salah satu dari 35 Kabupaten / Kota di Propinsi Jawa Tengah, terletak antara $110^{\circ} 22^{\prime}-110^{\circ}$ 50' Bujur Timur dan $7^{\circ} 7^{\prime}-7^{\circ} 36^{\prime}$ Lintang Selatan, dengan ketinggian antara 75-1500 meter di atas permukaan laut.Wilayah Kabupaten Boyolali dibatasi oleh :

Sebelah Utara : Kabupaten Grobogan dan Kabupaten Semarang.

Sebelah Timur : Kab. Karanganyar, Kab. Sragen

Sebelah Selatan : Kabupaten Klaten dan Daerah Istimewa Jogjakarta.

Sebelah Barat : Kabupaten Magelang dan Kabupaten Semarang. 
Kecamatan Mojosongo merupakan salah satu dari 13 kecamatan yang ada diwilayah Kabupaten Boyolali. Kecamatan Mojosongo berada pada ketinggian 100$400 \mathrm{~m}$ dpl dengan iklim tropis. Suhu udara $26^{\circ} \mathrm{C}$, sedangkan kelembaban udara berkisar antara 74\%. Luas wilayah di Kecamatan Mojosongo 4.341,1644 ha dengan penggunaan lahan sebagai tanah sawah 942,7496 ha dan tanah kering 3.398,4148 ha.

Kecamatan Cepogo merupakan salah satu dari 15 kecamatan yang ada diwilayah Kabupaten Boyolali. Kecamatan Cepogo beriklim sedang dengan curah hujan 2415 Mm dengan jumlah hari hujan $160 \mathrm{Hh}$. Suhu udara $21-32^{0}$ C. Geomorfologi Kecamatan Cepogo merupakan perbukitan bergelombang berelief halus hingga kasar antara 400 hingga 1.400 meter diatas permukaan laut, yang terbagi menjadi 2 satuan geomorfologi, yaitu perbukitan berelief halus-datar (menempati wilayah bagian timur dan memanjang ke arah tenggara) dan perbukitan berelief sedang (menempati bagian tengah hingga barat daya dan barat laut). Luas wilayah di Kecamatan Cepogo 5.299,8000 dengan penggunaan lahan sebagai tanah sawah 55,8000 dan tanah kering 5.244,0000.

\section{Identitas Responden}

Responden dalam penelitian ini adalah keluarga yang memelihara dan memiliki sapi perah laktasi di Kecamatan Mojosongo dan Kecamatan Cepogo, yang tergabung dalam anggota kelompok tani ternak (KTT) Kabupaten Boyolali dengan rincian pada Tabel 1. Identitas responden di Kecamatan Mojosongo dan Kecamatan Cepogo didominasi oleh pria. Kecamatan Mojosongo sebagian besar peternak berusia 41-50 tahun yang paling dominan melakukan usaha sapi perah yaitu sebesar $51,16 \%$ dan kecamatan Cepogo sebagian besar peternak berusia 41-60 tahun yaitu sebesar $43,48 \%$. 
Tabel 1. Karakteristik Responden Anggota KTT pada Kecamatan Mojosongo dan Kecamatan Cepogo.

\begin{tabular}{|c|c|c|c|c|c|}
\hline \multirow{3}{*}{ No } & \multirow{3}{*}{ Aspek } & \multicolumn{4}{|c|}{ Identitas Responden } \\
\hline & & \multicolumn{2}{|c|}{$\begin{array}{l}\text { Kecamatan } \\
\text { Mojosongo }\end{array}$} & \multicolumn{2}{|c|}{$\begin{array}{c}\text { Kecamatan } \\
\text { Cepogo }\end{array}$} \\
\hline & & Jumlah & Persentase & Jumlah & Persentase \\
\hline & & (Jiwa) & $(\%)$ & (Jiwa) & $(\%)$ \\
\hline \multirow[t]{4}{*}{1} & Jenis Kelamin & & & & \\
\hline & a. Laki-laki & 43 & 100,00 & 23 & 100,00 \\
\hline & b. Perempuan & - & - & - & - \\
\hline & Jumlah & 43 & 100,00 & 23 & 100,00 \\
\hline \multirow[t]{7}{*}{2} & Usia & & & & \\
\hline & a. 21-30 tahun & - & - & - & - \\
\hline & b. 31-40 tahun & 1 & 2,33 & 1 & 4,35 \\
\hline & c. 41-50 tahun & 22 & 51,16 & 10 & 43,48 \\
\hline & d. 51-60 tahun & 16 & 37,20 & 10 & 43,48 \\
\hline & e. $>60$ tahun & 4 & 9,30 & 2 & 8,69 \\
\hline & Jumlah & 43 & 100,00 & 23 & 100,00 \\
\hline \multirow[t]{6}{*}{3} & Tingkat pendidikan & & & & \\
\hline & a. Tidak sekolah & - & - & - & - \\
\hline & b. SD-SMP & 36 & 83,72 & 19 & 82,61 \\
\hline & c. SMA-Diploma & 5 & 11,63 & 3 & 13,04 \\
\hline & d. Sarjana & 2 & 4,65 & 1 & 4,35 \\
\hline & Jumlah & 43 & 100,00 & 23 & 100,00 \\
\hline \multirow[t]{7}{*}{4} & Mata pencaharian & & & & \\
\hline & a. Bertani & 10 & 23,25 & 6 & 26,08 \\
\hline & b. Beternak & 31 & 72,09 & 17 & 73,91 \\
\hline & c. Pedagang & - & - & - & - \\
\hline & d. PNS & 2 & 4,65 & - & - \\
\hline & e. Swasta & - & - & - & - \\
\hline & Jumlah & 43 & 100,00 & 23 & 100,00 \\
\hline \multirow[t]{6}{*}{5} & Pengalaman beternak & & & & \\
\hline & a. $0-10$ tahun & - & - & - & - \\
\hline & b. 11-20 tahun & 11 & 25,58 & 12 & 52,17 \\
\hline & c. $21-30$ tahun & 19 & 44,18 & 11 & 47,83 \\
\hline & d. $>31$ tahun & 13 & 30,23 & - & - \\
\hline & Jumlah & 43 & 100,00 & 23 & 100,00 \\
\hline
\end{tabular}

Tingkat pendidikan formal responden di daerah penelitian Kecamatan Mojosongo adalah tamatan SD-SMP yaitu $36(83,72 \%)$ orang dan Kecamatan Cepogo 19 orang $(82,61 \%)$. Pendidikan yang rendah akan mempengaruhi ketrampilan usaha tani. Menurut Sa'id dan Intan (2000) pendidikan adalah suatu proses alih teknologi dan trasformasi menyangkut dengan peningkatan pengetahuan melalui institusi atau lembaga tertentu dan dikelola secara formal dalam kurun waktu tertentu, yang merupakan proses teknik serta metode belajar mengajar untuk mengalihkan suatu pengetahuan dari suatu individu yang memerlukannya.

Mata pencaharian di Kecamatan Mojosongo dan Cepogo mayoritas terdapat di dua sektor yaitu peternakan dan pertanian. Beternak dengan 31 orang $(72,09 \%)$, pertanian 10 orang $(23,25 \%)$ di Kecamatan Mojosongo dan di Kecamatan Cepogo beternak 17 orang $(73,91 \%)$, pertanian 6 orang $(26,08 \%)$. Pengalaman beternak responden Kecamatan Mojosongo sebagian besar adalah 11-20 tahun yaitu 
sebanyak 19 peternak $(44,18 \%)$ sedangkan pada Kecamatan Cepogo pengalaman beternak sebagian besar adalah 11-20 tahun dengan 12 peternak $(52,17 \%)$. Tingkat pengalaman beternak responden yang relatif sama ini membuat tingkat pengetahuan dan ketrampilannya relatif sama. Pengalaman dapat dijadikan pedoman dalam menghadapi permasalahan yang dihadapi. Menurut Malthis dan Jhonshon (2001) menyatakan bahwa pengalaman adalah waktu yang digunakan oleh seseorang untuk memperoleh pengetahuan, keterampilan, dan sikap sesuai dengan tugas yang dibebankan kepadanya.

\section{Kepemilikan Ternak}

Berdasarkan data primer pada peternak Kecamatan Mojosongo dan Cepogo rata-rata kepemilikan ternak sapi laktasi sebesar 6,98 UT, jantan 0,26 UT, sapi dara sebesar 0,27 UT, dan pedet sebesar 0,39 UT. Kepemilikan Ternak di Kecamatan Mojosongo dan Cepogo dapat dilihat pada Tabel 2.

Tabel 2. Kepemilikan Ternak di Kecamatan Mojosongo, dan Cepogo.

\begin{tabular}{|c|c|c|c|c|c|}
\hline \multirow{3}{*}{ No } & \multirow{3}{*}{ Aspek } & \multicolumn{4}{|c|}{ Kepemilikan Ternak } \\
\hline & & \multicolumn{2}{|c|}{$\begin{array}{l}\text { Kecamatan } \\
\text { Mojosongo }\end{array}$} & \multicolumn{2}{|c|}{$\begin{array}{c}\text { Kecamatan } \\
\text { Cepogo }\end{array}$} \\
\hline & & Jumlah & Persentase & Jumlah & Persentase \\
\hline \multirow{6}{*}{1} & & (Peternak) & $(\%)$ & (Peternak) & $(\%)$ \\
\hline & Sapi laktasi(UT) & & & & \\
\hline & a. $<3$ & - & 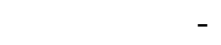 & - & \\
\hline & b. $=3$ & - & - & 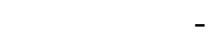 & \\
\hline & c. $>3$ & 43 & 100,00 & 23 & 100,00 \\
\hline & Jumlah & 43 & 100,00 & 100 & 100,00 \\
\hline \multirow[t]{5}{*}{2} & Sapi dara (UT) & & & & \\
\hline & a. $<1$ & 38 & 88,37 & 17 & 73,91 \\
\hline & b. $=1$ & 5 & 11,63 & 6 & 26,08 \\
\hline & c. $>1$ & - & - & - & \\
\hline & Jumlah & 43 & 100,00 & 23 & 100,00 \\
\hline \multirow[t]{5}{*}{3} & Sapi jantan (UT) & & & & \\
\hline & a. $<1$ & 37 & 86,04 & 15 & 65,22 \\
\hline & b. $=1$ & 6 & 13,95 & 5 & 21,74 \\
\hline & c. $>1$ & - & 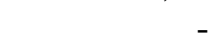 & 3 & 13,04 \\
\hline & Jumlah & 43 & 100,00 & 23 & 100,00 \\
\hline \multirow[t]{5}{*}{4} & Pedet (UT) & & & & \\
\hline & a. $<0,5$ & 13 & 30,23 & 13 & 56,52 \\
\hline & b. $=0,5$ & 25 & 58,14 & 7 & 30,43 \\
\hline & c. $>0,5$ & 5 & 11,63 & 3 & 13,04 \\
\hline & Jumlah & 43 & 100,00 & 100 & 100,00 \\
\hline
\end{tabular}

Pada peternak Kecamatan Mojosongo rata-rata kepemilikan ternak sapi laktasi sebesar 6,74 UT, sapi dara sebesar 0,24 UT, sapi jantan sebesar 0,13 UT, dan pedet sebesar 0,42 UT. Peternak Kecamatan Cepogo rata-rata kepemilikan ternak sapi laktasi sebesar 6,74 UT, sapi dara sebesar
0,33 UT, sapi jantan sebesar 0,48 UT, dan pedet sebesar 0,35 UT. Menurut Sudono et al. (2003) menyatakan bahwa usaha sapi perah mengguntungkan memiliki sapi perah laktasi sebesar $60 \%$ dan non laktasi $40 \%$. Di tambahkan oleh Rusdiana et al. (2009) yang menyatakan bahwa usaha tani sapi 
perah menguntungkan dan berkelanjutan apabila pemilikan minimal 5,23 unit ternak atau 6 ekor sapi dan proporsi sapi laktasi $70 \%$. Sementara itu, skala ekonomis dapat dicapai dengan kepemilikan 10-12 ekor sapi per peternak.

\section{Biaya Produksi}

Biaya produksi terdiri dari biaya tetap dan biaya tidak tetap. Macam biaya produksi yang dikeluarkan setiap peternak berbeda-beda karena jumlah ternak yang dimiliki juga berbeda. Menurut Royan (2009) biaya produksi merupakan pengorbanan yang digunakan sebelum proses produksi berlangsung pada waktu tertentu. Biaya produksi dapat berupa biaya tetap dan tidak tetap. Hal ini sesuai dengan pendapat Rusdiana dan Sejati (2009) yang menyatakan bahwa Jenis biaya produksi dapat dibagi menjadi biaya tetap dan biaya tidak tetap. Biaya tetap merupakan biaya yang jumlahnya tidak tergantung pada besar kecilnya produksi. Sedangkan biaya tidak tetap besar kecilnya tergantung pada produksi dan besarnya biaya pengeluaran. Biaya produksi yang dikeluarkan oleh peternak di Kecamatan Cepogo dan Mojosongo terdiri dari biaya tetap dan biaya tidak tetap dilihat pada Tabel 3 . Berdasarkan tabel besarnya biaya rata-rata produksi total Kecamatan Mojosongo yang di keluarkan seorang peternak Rp 3.350.009,00 per bulan. Biaya tetap ratarata tiap peternak Rp 1.168.219,00. Biaya tidak tetap rata-rata tiap peternak $\mathrm{Rp}$ 2.181.790,00. Sedangkan, biaya rata-rata produksi total Kecamatan Cepogo yang di keluarkan seorang peternak Rp 2.986.118,00 per bulan. Biaya tetap ratarata tiap peternak $\mathrm{Rp} 867.303,00$. Biaya tidak tetap rata-rata tiap peternak $\mathrm{Rp}$ 2.118.815,00.

Tabel 3. Biaya Produksi Peternak Kecamatan Mojosongo dan Cepogo/Bulan.

\begin{tabular}{|c|c|c|c|c|c|}
\hline \multirow[t]{2}{*}{ No. } & \multirow{2}{*}{ Biaya } & \multicolumn{2}{|c|}{ Kecamatan Mojosongo } & \multicolumn{2}{|c|}{ Kecamatan Cepogo } \\
\hline & & Rata-rata & Jumlah/Bulan & Rata-rata & Jumlah/Bulan \\
\hline & Biaya Tetap & ------------ & $--\mathrm{Rp}--$ & 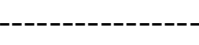 & \\
\hline 1 & Penyusutan Kandang & 1.039 .360 & & 738.445 & \\
\hline 2 & Penyusutan Peralatan & 33.943 & & 30.928 & \\
\hline \multirow[t]{2}{*}{3} & Penyusutan Ternak & 94.916 & & 97.929 & \\
\hline & $\begin{array}{l}\text { Jumlah } \\
\text { Biaya Tidak Tetap }\end{array}$ & & 1.168 .219 & & 867.303 \\
\hline 1 & Konsentrat & 1.766 .197 & & 1.700 .511 & \\
\hline 2 & Jerami & 335.593 & & 338.304 & \\
\hline 3 & Obat-obatan & 20.000 & & 20.000 & \\
\hline \multirow[t]{3}{*}{4} & IB (Inseminasi Buatan) & 60.000 & & 60.000 & \\
\hline & Jumlah & & 2.181 .790 & & 2.118 .815 \\
\hline & Jumlah Total & & 3.350 .009 & & 2986118 \\
\hline
\end{tabular}

\section{Penerimaan}

Penerimaan usaha ternak sapi perah peternak anggota KTT di Kecamatan Mojosongo dan Cepogo, Kabupaten Boyolali meliputi hasil penjualan ternak, produksi susu dan perhitungan kotoran ternak. Hal ini sesuai dengan pendapat
Soekartawi (1995) yang menyatakan bahwa penerimaan dari usaha sapi perah terdiri dari penjualan susu dan kotoran. Besarnya penerimaan dari hasil usaha ternak rata-rata sebesar Rp 10.487.421,00 untuk Kecamatan Mojosongo dan $\mathrm{Rp}$ 10.310.226,00 untuk 
Kecamatan Cepogo. Perincian penerimaan dapat dilihat pada Tabel 4.

Tabel 4. Penerimaan Usaha Ternak Sapi Perah KTT Di Kecamatan Mojosongo dan Cepogo/Bulan.

\begin{tabular}{|c|c|c|c|c|c|}
\hline \multirow{2}{*}{ No. } & \multirow{2}{*}{ Penerimaan } & \multicolumn{2}{|c|}{ Kecamatan Mojosongo } & \multicolumn{2}{|c|}{ "Kecamatan Cepogo } \\
\hline & & Rata-rata & Persentase & Rata-rata & Persentase \\
\hline & & -------Rp------- & -----\%------ & & \\
\hline 1 & Produksi Susu & 10.437 .421 & 99,52 & 10.260 .226 & 99,51 \\
\hline 2 & Kotoran & 50.000 & 0,47 & 50.000 & 0,48 \\
\hline & Jumlah & 10.487 .421 & 100 & 10.310 .226 & 100 \\
\hline
\end{tabular}

Persentase terbesar penerimaan di Kecamatan Mojosongo dan Cepogo berasal dari hasil penjualan susu $99,52 \%$ dan 99,51 $\%$. besarnya persentase penerimaan dari hasil penjualan susu disebabkan karena produksi susu yang tinggi dan jumlah kepemilikan ternak sapi perah laktasi oleh peternak yang relatif besar serta harga jual dari susu yang sesuai dengan kualitas susu. Hal ini sesuai dengan pendapat oleh Hariyono (2006) dalam jurnalnya yang menyatakan bahwa besar kecilnya penerimaan usaha ternak sapi perah akan sangat tergantung pada jumlah susu yang diproduksi dan harga jual susu.

\section{Pendapatan}

Besarnya pendapatan rata-rata usaha ternak pada KTT di Kecamatan Mojosongo adalah Rp 1.327.996,00 dan Kecamatan Cepogo Rp 2.312.258,00. Rincian pendapatan usaha ternak sapi perah dapat dilihat pada Tabel 5. Pendapatan usahatani digunakan untuk memenuhi kebutuhan sehari-hari. Pendapatan digunakan untuk mengetahui kentungan maupun kerugian yang didapat dalam usaha. Hal ini sesuai dengan pendapat Hernanto (1996) yang menyatakan bahwa Pendapatan adalah penerimaan setelah dikurangi biaya-biaya. Dengan mengetahui pendapatan yang diterima peternak akan mengetahui untuk atau rugi dalam usaha. Hasil tersebut menunjukkan bahwa pendapatan peternak di Kecamatan Mojosongo dan Kecamatan Cepogo bernilai positif. Pendapatan yang tinggi dapat dipengaruhi oleh jumlah sapi lakrtasi dan produksi susu. Hal ini sesuai dengan pendapat Sudiyono (2001) yang menyatakan bahwa banyaknya jumlah kepemilikan ternak berpengaruh pada pendapatan, semakin banyak kepemilikan ternak maka pendapatannya juga semakin bertambah besar, sedangkan apabila terjadi kerugian juga akan menerima kerugian yang besar pula.

Tabel 5. Pendapatan Peternak Anggota KTT /Bulan

\begin{tabular}{llcc}
\hline No. & \multicolumn{1}{c}{ Biaya } & $\begin{array}{c}\text { Kecamatan Mojosongo } \\
\text { Rata-rata }\end{array}$ & $\begin{array}{c}\text { Kecamatan Cepogo } \\
\text { Rata-rata }\end{array}$ \\
\hline & & --1.168 .219 & 867.303 \\
1 & Biaya Tetap & 2.181 .790 & 2.118 .815 \\
2 & Biaya Tidak Tetap & 5.372 .022 & 5.298 .376 \\
3 & Penerimaan & 1.327 .996 & 2.312 .258 \\
\hline \multicolumn{2}{r}{ Pendapatan } & & \\
\hline
\end{tabular}


KESIMPULAN DAN SARAN

\section{Kesimpulan}

Berdasarkan hasil analisis dan pembahasan dapat disimpulkan adalah sebagai berikut :

1) Pendapatan peternak di Kecamatan Mojosongo, dan Kecamatan Cepogo menguntungkan dengan rata-rata pendapatan peternak sapi perah di Kecamatan Mojosongo Rp 1.327.996,00 dan Kecamatan Cepogo Rp 2.312.258,00

2) Pendapatan peternak tertinggi di Kecamatan Cepogo dan diikuti dengan pendapatan peternak di Kecamatan Mojosongo.

\section{Saran}

Disarankan untuk mendapatkan pendapatan yang tinggi, perlu meningkatkan produksi susu, dengan asumsi harga susu tidak turun, sebab besar kecilnya penerimaan usaha ternak sapi perah akan sangat tergantung pada jumlah susu yang diproduksi dan harga jual susu.

\section{DAFTAR PUSTAKA}

Hariyono, M. B. 2006. Faktor-faktor yang Berpengaruh Terhadap Produksi Susu pada Usaha Ternak Sapi Perah. Jurnal Sosial Ekonomi Peternakan. 2 (2) : 78-79.

Hernanto, F. 1996. Ilmu Usaha Tani. Penebar Swadaya, Jakarta.

Royan, Frans. 2009. Cara Gampang dan Praktis Merancang Pemasaran Usaha Kecil - Menengah. Dahara Prize, Semarang.

Rusdiana, S. Dan W. K. Sejati. 2009. Upaya pengembangan agribisnis sapi perah dan peningkatan produksi susu melalui pemberdayaan koperasi susu. Forum Penelitian Agroekonomi 27 (1) : 43-51.

Sa'id, E.G dan A. H. Intan. 2000. Manajemen Agribisnis. Ghalia Indonesia, Jakarta.

Soekartawi, 1995. Analisis Usaha tani. Penerbit Universitas Indonesia. UIPress. Jakarta.

Sudiyono,

A.2001.Pemasaran

Pertanian. Penerbit Universitas

Muhammadiyah Malang. UMM Press, Malang.

Sudono, A., R. F. Rosdiana dan B. Setiawan. 2003. Petunjuk Praktis Beternak Sapi Perah Secara Intensif. Cetakan Pertama. Agromedia Pustaka, Jakarta. 